\title{
Stress transfer from pile group in saturated and unsaturated soil using theoretical and experimental approaches
}

\author{
Raid R. al-Omari ${ }^{1, *}$, Mohammed Y. Fattah ${ }^{2}$, and Abbas M. Kallawi ${ }^{3}$ \\ ${ }^{1}$ Professor, Civil Engineering Department, College of Engineering, Al-Nahrain University, Baghdad, \\ Iraq. Email: tosharaid@yahoo.com. \\ 2 Professor, Building and Construction Engineering Department, University of Technology, Baghdad, \\ Iraq. Email: myf_1968@yahoo.com. \\ ${ }^{3}$ Lecturer, University of Baghdad, Baghdad, Iraq. Email: mabbas153@yahoo.com.
}

\begin{abstract}
Piles are often used in groups, and the behavior of pile groups under the applied loads is generally different from that of single pile due to the interaction of neighboring piles, therefore, one of the main objectives of this paper is to investigate the influence of pile group (bearing capacity, load transfer sharing for pile shaft and tip) in comparison to that of single piles. Determination of the influence of load transfer from the pile group to the surrounding soil and the mechanism of this transfer with increasing the load increment on the tip and pile shaft for the soil in saturated and unsaturated state (when there is a negative pore water pressure). Different basic properties are used that is $\left(\mathrm{S}=90 \%, \gamma_{\mathrm{d}}=15 \mathrm{kN} / \mathrm{m}^{3}, \mathrm{~S}=90 \%, \gamma_{\mathrm{d}}=17 \mathrm{kN} / \mathrm{m}^{3}\right.$ and $\left.\mathrm{S}=60 \%, \gamma_{\mathrm{d}}=15 \mathrm{kN} / \mathrm{m}^{3}\right)$. Seven model piles were tested, these was: single pile (compression and pull out test), $2 \times 1,3 \times 1,2 \times 2,3 \times 2$ and $3 \times 3$ group. The stress was measured with $5 \mathrm{~cm}$ diameter soil pressure transducer positioned at a depth of $5 \mathrm{~cm}$ below the pile tip for all pile groups. The measured stresses below the pile tip using a soil pressure transducer positioned at a depth of $0.25 \mathrm{~L}$ (where $\mathrm{L}$ is the pile length) below the pile tip are compared with those calculated using theoretical and conventional approaches. These methods are: the conventional $2 \mathrm{~V}: 1 \mathrm{H}$ method and the method used the theory of elasticity. The results showed that the method of measuring the soil stresses with soil pressure transducer adopted in this study, gives in general, good results of stress transfer compared with the results obtained from the theoretical and conventional approaches.
\end{abstract}

\section{Introduction}

The bearing capacity of unsaturated soils can be viewed as an extension of saturated soil mechanics. The unsaturated soil can be visualized as having a cohesion consisting of two components. One component is the effective cohesion, and the other component is due to matric suction which is usually ignored in the conventional bearing capacity analysis, with this concept, the conventional bearing capacity theory is applicable to unsaturated soils [1].

\footnotetext{
*Correspondingauthor: myf_1968@yahoo.com
} 
The stresses on the underlying strata produced by piles are difficult to estimate for several reasons [2]:

1. Influence of pile cap especially when it is in direct contact with the ground.

2. Unknown friction and end bearing effect on pile.

3. Overlap of stresses from adjacent piles, which is difficult to evaluate.

4. Influence of driving piles on the adjacent soil.

5. Time dependent effect such as consolidation, thixotropy, varying load and change in ground water table.

The typical stresses/soil pressures produced from shaft friction or end bearing of a single pile and a group of piles are shown in Figure 1. If piles are used in groups, there may be an overlap of stresses, as shown in Figure $1 \mathrm{~b}, \mathrm{~d}$ and e, if the spacing is too close. If the overlap is large, the soil may fail in shear or settlement. Though, the overlapping zone of stresses obviously decreases with increased pile spacing, it may not be feasible since the pile cap size becomes too large and hence expensive [3].

For these reasons, it is common practice to simplify the stress computation, the load is assumed to spread from fictitious rigid footing located at a depth of L/3 from the bottom of the pile. Using the theory of elasticity as presented in Bowles (1996) [2], for three cases of stress distribution, illustrated in Figure 2, these are:

Case1: end bearing, Case 2: constant skin friction, and Case 3: linear variation of skin friction. The stress is obtained as:

$$
\sigma_{\mathrm{z}}=\frac{\mathrm{P}}{\mathrm{L}_{\mathrm{p}}^{2}} \mathrm{~K}_{\mathrm{z}}
$$

where: $\sigma_{z}=$ vertical stress, $P=$ applied load, $L_{p}=$ embedment pile length and $K_{z}=$ stress coefficient.

The stress coefficient $\mathrm{K}_{\mathrm{z}}$ is obtained from the equations presented for every case mentioned or directly from tables presented in the same reference.

Vanapalli and Taylan (2011, 2012), suggested more experimental and numerical studies in progress to check the validity of the modified $\alpha, b$ and $\lambda$ methods for different coarse and fine-grained soils [4-5]. These studies will be useful to better understand the influence of matric suction on the load carrying capacity of the piles. They also suggested different techniques of testing to alleviate some experimental problems. For instance, instead of drilling a hole into the initially compacted soil, they suggested compacting the soil around the pile using a specially designed compactor, such a technique would reduce disturbance during pile installation for tests and likely provide better correlation results as it eliminates the problems associated with the soil disturbance. In addition, this technique also provides better contact between the pile and the soil.

Mohsen (2012) [6] and Fattah et al., (2014) [7] investigated the behavior of a single pile in unsaturated soils using a pile foundation with $(0.6 \mathrm{~m})$ diameter and $(12 \mathrm{~m})$ length, embedded in fully saturated and partially saturated Iraqi soils, within Baghdad city. The analysis was carried out using the finite element programs SIGMA/W and SEEP/W.

The main objectives of the research are to investigate the influence of the following factors on the behavior of single and pile group foundation: Investigating the behavior of single pile and pile group foundation system in saturated and unsaturated soils. And studying the stress distribution within the soil system and below the pile tip and negative pore water pressure variation with water content. 


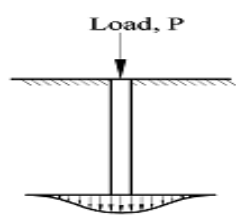

(a) Single pile

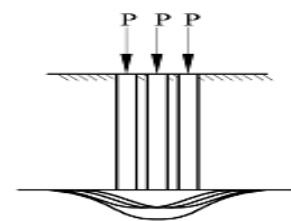

(b) Group of three piles A: End bearing piles Load, $\mathbf{P}$

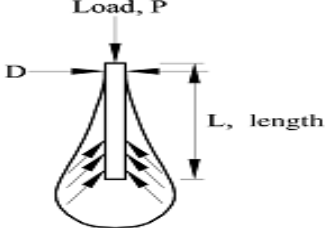

(c) Single pile

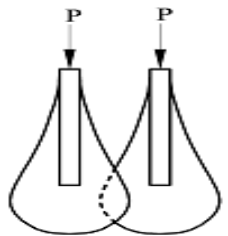

(d) Group of two piles

B: Friction piles

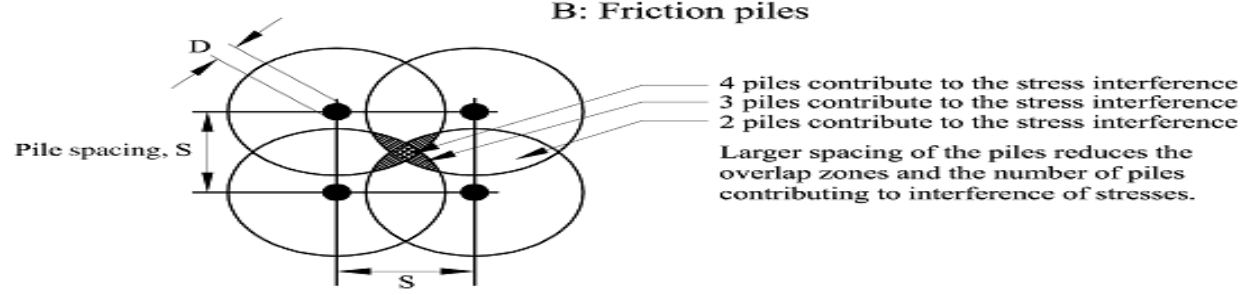

(e) Stress in soils due to pile groups

$C:$ Interference of stresses in pile groups

Fig. 1: Stresses in soil due to loads on single pile and pile groups [3].

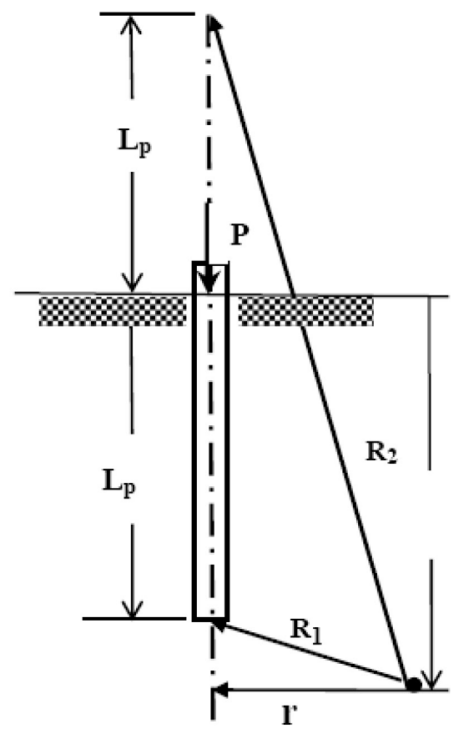

Case 1

$$
\begin{array}{lrr}
\mathbf{n}=\mathbf{r} / \mathbf{L}_{\mathrm{p}} \quad \mathbf{m}=\mathrm{z} / \mathrm{L}_{\mathrm{p}} & \mathbf{F}^{2}=\mathbf{m}^{2}+\mathbf{n}^{2} \\
\mathbf{A}^{2}=\mathbf{n}^{2}+(\mathbf{m}-1)^{2} & \mathbf{B}^{2}=\mathbf{n}^{2}+(\mathbf{m}+1)^{2}
\end{array}
$$

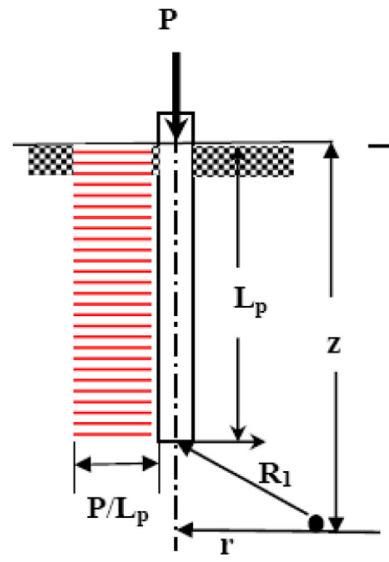

Case 2

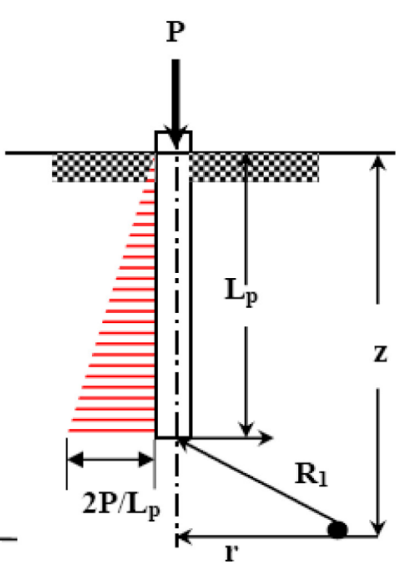

Case 3

Point (end-bearing) load

\section{Constant skin friction}

Linear variation of skin friction

Fig. 2: Pile - soil system for the evaluation of the soil stresses using Mindlin solution [2]. 


\section{Experimental Work}

Two sets of containers were used in the experimental work, These containers are designed to serve the saturation process and can be subdivided into three types according to the pile group tested as follows: Container 1 with internal dimensions of $20 \mathrm{~cm}$ length, $20 \mathrm{~cm}$ width and $35 \mathrm{~cm}$ height, this container was used for single pile test (compression and pull out test). Containers 2 with internal dimensions of $30 \mathrm{~cm}$ length, $30 \mathrm{~cm}$ width and $35 \mathrm{~cm}$ height, this container was used for pile of $(2 \times 1)$ and $(2 \times 2)$ group configuration. Container 3 with internal dimensions of $40 \mathrm{~cm}$ length, $30 \mathrm{~cm}$ width and $50 \mathrm{~cm}$ height, this container was used for pile groups of $(3 \times 1),(3 \times 2)$ and $(3 \times 3)$ configuration.

It should be noted that the spacing between piles is the same for all pile groups $\mathrm{s}=3$ (i.e. 6 $\mathrm{cm})$.

In saturated tests, the water was supplied to the container through a main water supply plastic tube of $10 \mathrm{~mm}$ diameter, this tube is branched into two pipes of the same diameter on every side of the container to ensure gradual and uniform saturation process from the base of the container to the surface (saturation was progressed from the bottom to the top of the soil surface in order to expel any entrapped air during saturation process). The physical and chemical properties of the soil used are illustrated in Table 1. According to the Unified Soil Classification System (USCS), the soil can be classified as (CL -ML) with $38 \%$ sand, $28 \%$ silt and $34 \%$ clay. Fattah et al. (2013) concluded that the maximum suction is measured for soils of low consistency (liquid limit $<40 \%$ ) [8].

Six model pile groups were tested, these are single pile, $2 \times 1,3 \times 1,2 \times 2,3 \times 2$ and $3 \times 3$ groups. The model piles used were made of aluminum metal with a square cross section (20 $\mathrm{mm} \times 20 \mathrm{~mm}$ ) and $1.2 \mathrm{~mm}$ thickness. The pile model was closed at the toe with an aluminum plate (closed end pile), and attached to the pile cap with two small aluminum angles $(20 \mathrm{~mm} \times 15 \mathrm{~mm}), 2 \mathrm{~mm}$ thick by two bolts and nuts as shown in Figure 3.

Table 1: Physical and chemical properties of soil used.

\begin{tabular}{|c|c|}
\hline Index property & Index value \\
\hline Optimum moisture content (OMC)\% & 13.3 \\
\hline Liquid limit \%( LL) & 25 \\
\hline Plastic limit \%(PL) & 19 \\
\hline Plasticity index\%(PI) & 6 \\
\hline Activity (Ac) & 0.19 \\
\hline Specific gravity (Gs) & 2.68 \\
\hline Gravel (larger than $4.76 \mathrm{~mm}$ )\% & 0 \\
\hline Sand (4.76 - $-0.074 \mathrm{~mm}) \%$ & 38 \\
\hline Silt $(0.074-0.005) \%$ & 28 \\
\hline Clay (less than $0.005 \mathrm{~mm}) \%$ & 34 \\
\hline Gypsum content \% & 0.8 \\
\hline Total dissolved salts TDS\% & 1.3 \\
\hline $\mathrm{SO}_{3}$ content $\%$ & 0.41 \\
\hline $\mathrm{pH}$ value & 8.73 \\
\hline $\mathrm{CaCO}_{3}$ content $\%$ & 30.7 \\
\hline Soil symbols (U.S.C.S) & CL-ML \\
\hline
\end{tabular}




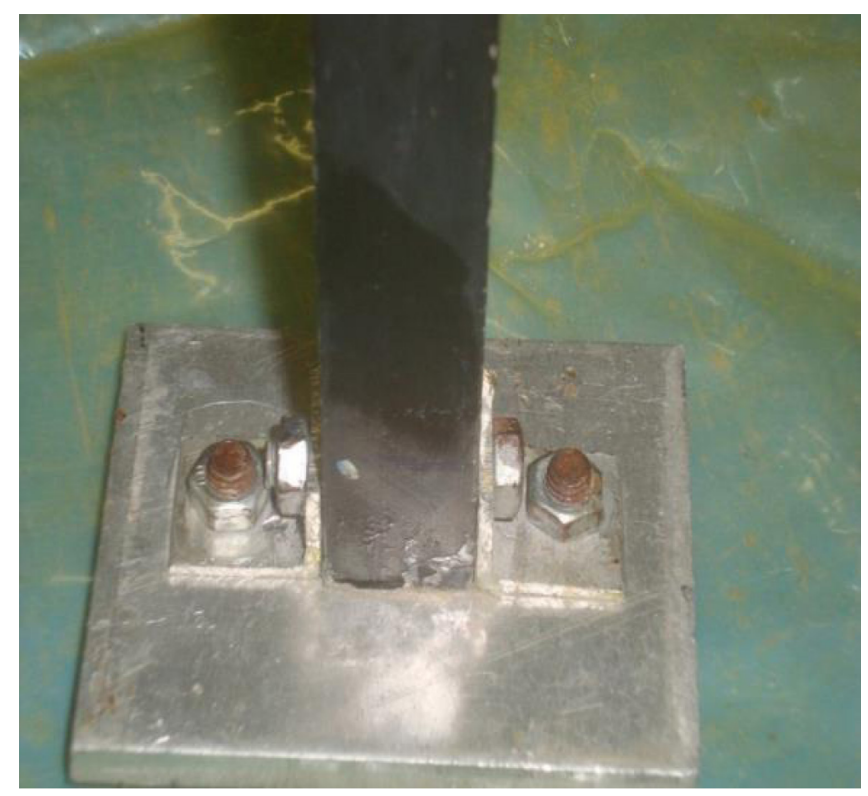

Fig. 3 Connecting the pile to pile cap.

All piles have a length of $200 \mathrm{~mm}$ to give an $\mathrm{L} / \mathrm{D}$ ratio $=10$, with the same spacing for all groups $s=3$. To facilitate and minimize the disturbance of the soil during pile inserting, another aluminum pile of square cross section $(15 \mathrm{~mm} \times 15 \mathrm{~mm})$ was used which is slightly smaller in cross section in comparison with the used pile. This pile was inserted prior to the pile installation to facilitate the pile jacking and minimize as possible the soil disturbance. After that, the pile group was jacked to the soil model slowly and checked within the jacking process to be in the horizontal alignment.

The cap used in the test was also modeled using aluminum plate with smooth surface and thickness of $6 \mathrm{~mm}$. It was connected to the pile group with bolts and nuts. The stresses below the pile groups are measured by soil pressure transducer type (KDE-200 kPa) located at $0.5 \mathrm{~L}(50 \mathrm{~mm})$ down the piles (center piles). The transducer is connected to a digital data logger (TC-32K) through a five channel switching box (CSW 5A).

The soil was prepared in accordance with the type of test (saturated or unsaturated), and the amount of soil according to the testing container adopted.

The saturated soil was prepared according to the following steps:

1. The sieved soil is prepared at a water content equal to $12.5 \%$ which is in the range of optimum moisture content.

2. Each $10 \mathrm{kgs}$ of conditioned soil is mixed gradually and thoroughly with an amount of water corresponding approximately to the water content of $12.5 \%$ by hand for a period of 10 minutes to give a uniform distribution of moisture content.

3. After mixing with water, the wet soil is kept in double tightened polythene sheets and left for about 2-4 days as a curing period. Two samples of the soil are extracted to check the actual water content, after that the pre-calculated amount of soil according to the box selected is spread to occupy $50 \mathrm{~mm}$ depth of the box. This quantity of soil is compacted to the desired depth using a special tamping steel hammer of $(100 \mathrm{~mm}$ $\mathrm{x} 100 \mathrm{~mm}$ ) in size. The soil is tamped according to the calculated dry density. Before placing the second layer using the same procedure, the surface of the first layer is scratched to give a good interaction with the next layer.

4. A pressure transducer device $50 \mathrm{~mm}$ diameter type $(\mathrm{KDE}-200 \mathrm{kPa})$ is located at $0.5 \mathrm{~L}$ $(5 \mathrm{~cm})$ down the piles (center piles). The transducer is connected to a digital data 
logger (TC-32K) through a five channel switching box (CSW 5A). The transducer is placed at a depth of $0.25 \mathrm{~L}(5 \mathrm{~cm})$ below the pile tip in all tests for stress measurements below the pile tip.

The same procedure for the saturated soil is used here except that the water content was pre calculated according to the selected degree of saturation.

Figure 4 shows details of the equipment that was designed to serve the objective of the proposed testing program. The loading frame was constructed using two steel channels (150 $\mathrm{mm} \times 50 \mathrm{~mm} \times 8 \mathrm{~mm}$ ), and $2 \mathrm{~m}$ length as supporting columns. They are connected with two other steel channels of the same dimensions, $1.2 \mathrm{~m}$ length. One of these channels was to fix the column channel against movement during the load application, while another channel was allowed to move vertically for about $500 \mathrm{~mm}$ according to the container length used during the test - full details are given by Khallawi, 2015 [9].

The vertical load was applied on the model piles by means of a hydraulic jack, the applied load was measured using a calibrated proving ring with $2 \mathrm{kN}$ capacity. A dial gauge with $0.01 \mathrm{~mm}$ accuracy was used for measuring settlements of the pile group model. The load is applied incrementally with a period of 5 minutes for every load increment as adopted in some pile load tests-U. S. Army Corps of Engineers, 1991 [10].

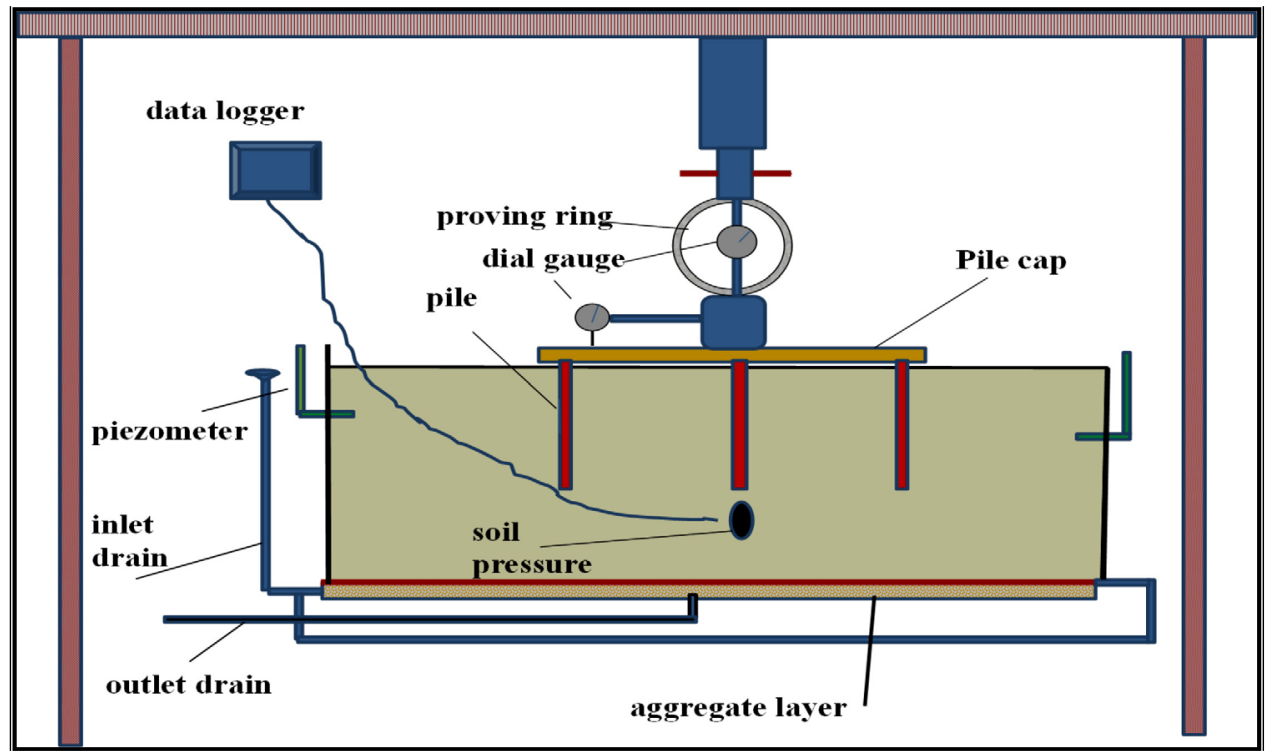

Fig. 4 Diagram of setup configuration.

\section{Results and discussion}

The results of comparison of stress transfer in saturated soil with properties $\left(\mathrm{S}=90 \%, \gamma_{\mathbf{d}}\right.$ $\left.=15 \mathrm{kN} / \mathrm{m}^{3}\right),\left(\mathrm{S}=90 \%, \gamma_{\mathbf{d}}=17 \mathrm{kN} / \mathrm{m}^{3}\right)$ and unsaturated soil with $\left(\mathrm{S}=60 \%, \gamma_{\mathbf{d}}=15 \mathrm{kN} / \mathrm{m}^{3}\right)$ are presented in Figures 5 to 7 for single, $2 \times 1,3 \times 1,2 \times 2,3 \times 2$ and $3 \times 3$ pile groups, respectively.

These figures show a good agreement between the results of experimental and the theatrical approach, it can be noticed that the vertical pressure in experimental work is not varying linearly with the applied load, while the linear line is obtained for theoretical analysis. That may cause the stress transfer below the pile tip measured from experimental work is more reasonable than that of the theoretical and conventional $2 \mathrm{~V}: \mathrm{H}$ methods because the experimental results show that the tip resistance increases rapidly before pile 
failure, while the other two methods consider that the tip resistance is constant throughout the test.

Further, for theoretical analysis, the stress is transferred to the pile tip and shaft by a linear variation and the percentage of load shared by the shaft and tip is calculated according to final results of load shared between the shaft and tip obtained from the experimental work for all pile groups. These values are also presented in Tables 2, 3 and 4. Further The Poisson's ratio used in the theoretical analysis is 0.4 is used for saturated soil, while a value of 0.2 is used for unsaturated soil as suggested by Bowles (1996) [2].

Table 2: Percentage of stress values used in the analysis of soil $\left(\mathrm{S}=90 \%, \gamma_{\mathbf{d}}=15 \mathrm{kN} / \mathrm{m}^{3}\right.$.

\begin{tabular}{|c|c|c|c|c|c|c|}
\hline Pile group & Single & $\mathbf{2 x 1}$ & $\mathbf{3 x 1}$ & $\mathbf{2 x 2}$ & $\mathbf{3 x 2}$ & $\mathbf{3 x 3}$ \\
\hline \% shaft & 50 & 75 & 90 & 90 & 90 & 95 \\
\hline \% tip & 50 & 25 & 10 & 10 & 10 & 5 \\
\hline
\end{tabular}

Table 3: Percentage of stress values used in the analysis of soil $\left(\mathrm{S}=90 \%, \gamma_{\mathbf{d}}=17 \mathrm{kN} / \mathrm{m}^{3}\right)$.

\begin{tabular}{|c|c|c|c|c|c|c|}
\hline Pile group & Single & $\mathbf{2 x 1}$ & $\mathbf{3 x 1}$ & $\mathbf{2 x 2}$ & $\mathbf{3 x 2}$ & $\mathbf{3 x 3}$ \\
\hline \% Shaft & 50 & 75 & 85 & 90 & 90 & 95 \\
\hline \% Tip & 50 & 25 & 15 & 10 & 10 & 5 \\
\hline
\end{tabular}

Table 4: Percentage of stress values used in the analysis of soil $\left(\mathrm{S}=60 \%, \gamma_{\mathbf{d}}=15 \mathrm{kN} / \mathrm{m}^{3}\right.$.

\begin{tabular}{|c|c|c|c|c|c|c|}
\hline Pile group & Single & $\mathbf{2 x 1}$ & $\mathbf{3 x 1}$ & $\mathbf{2 x 2}$ & $\mathbf{3 x 2}$ & $\mathbf{3 x 3}$ \\
\hline \% Shaft & 0 & 70 & 80 & 88 & 90 & 92 \\
\hline \% Tip & 100 & 30 & 20 & 12 & 10 & 8 \\
\hline
\end{tabular}

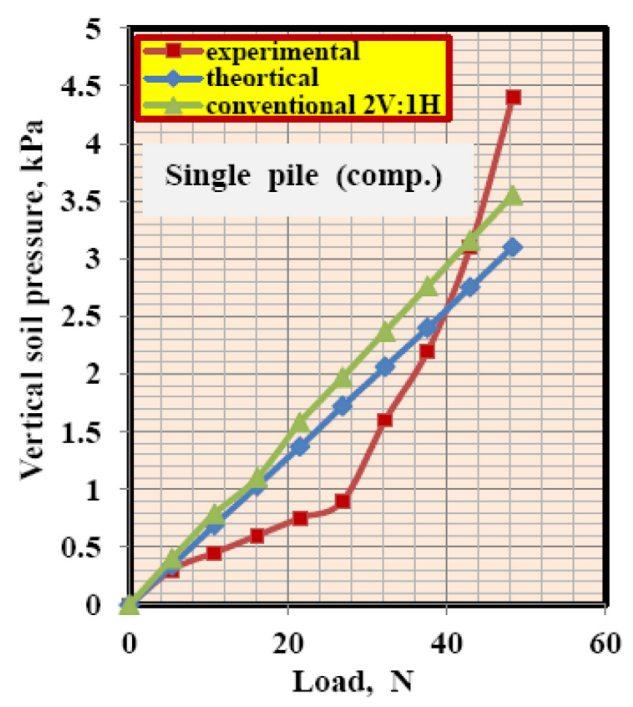

a. Single pile.

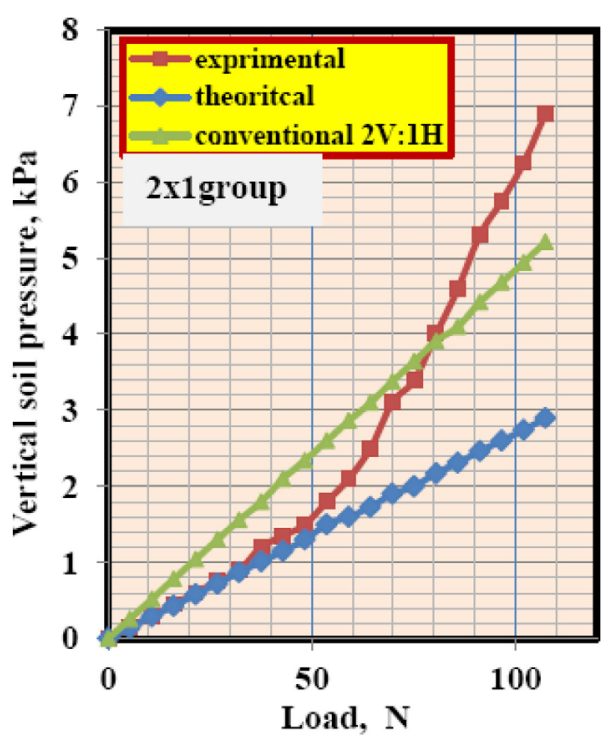

b. $2 \times 1$ group. 

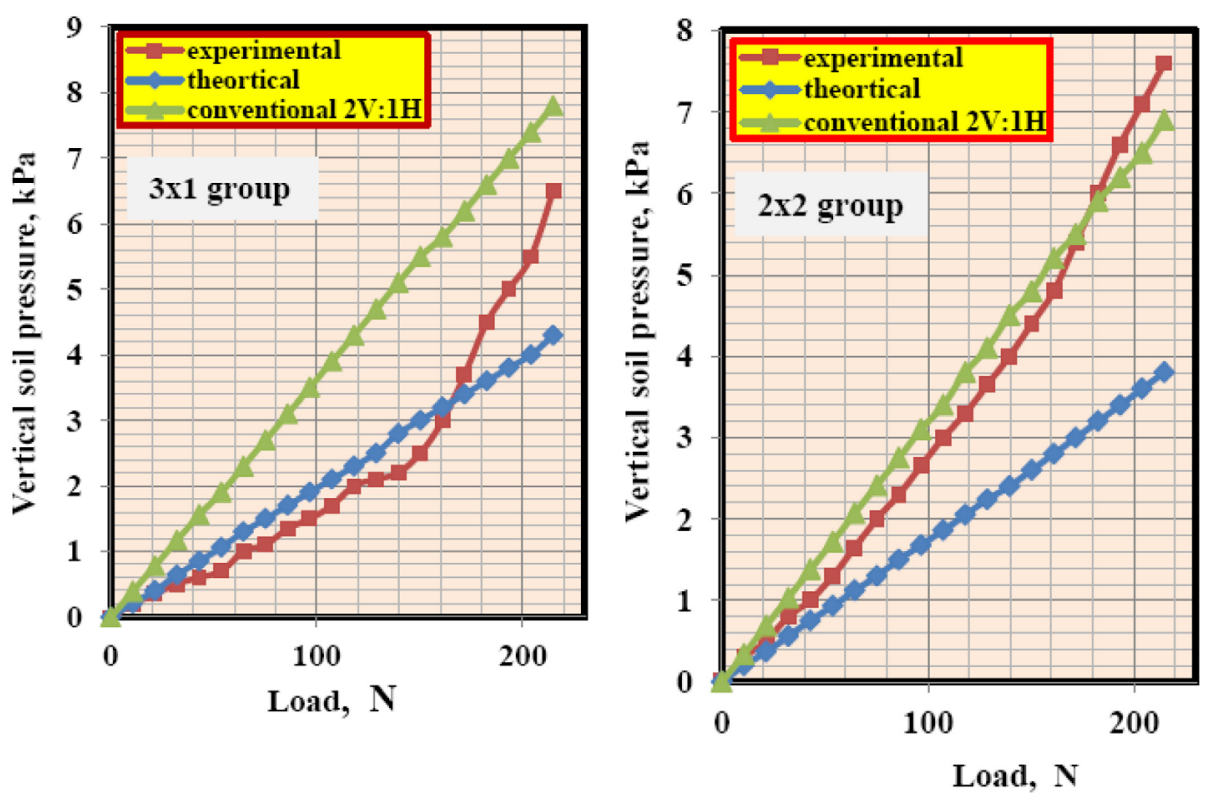

c. $3 \times 1$ group.
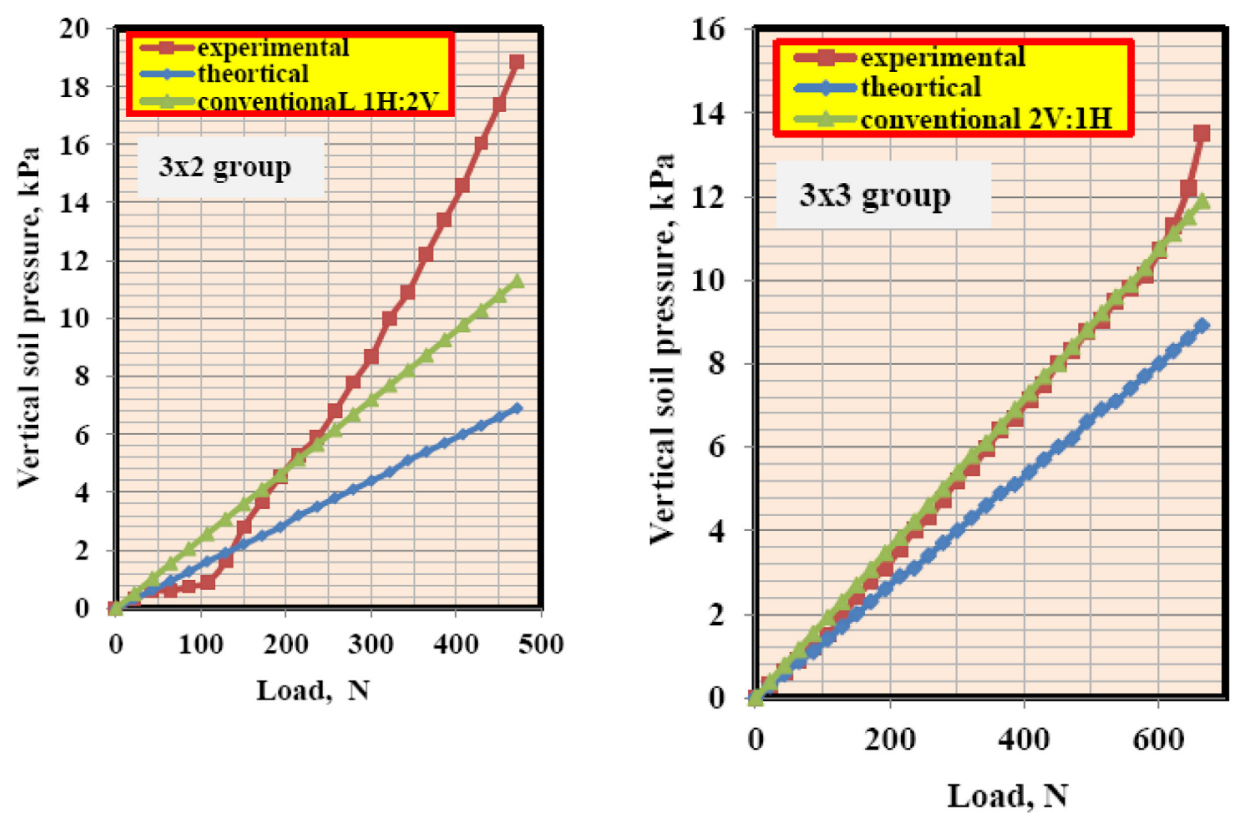

e. $3 \times 2$ group.

f. $3 \times 3$ group.

Fig. 5 Stress transfer below the pile tip during the load application to single and pile group pile in saturated soil $\left(\mathrm{S}=90 \%, \gamma_{\mathrm{d}}=15 \mathrm{kN} / \mathrm{m}^{3}\right)$ compared with that of theoretical and conventional $2 \mathrm{~V}: 1 \mathrm{H}$ approaches. 


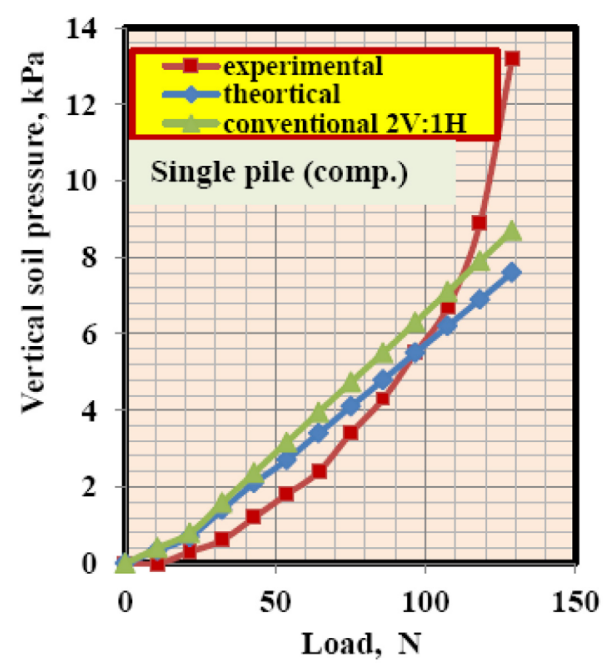

a. Single pile.

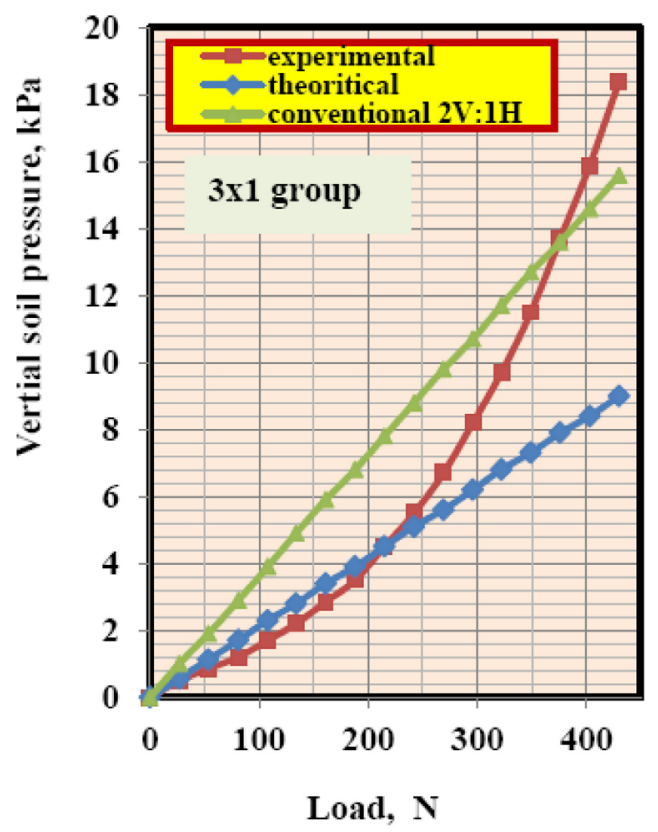

c. $3 \times 1$ group

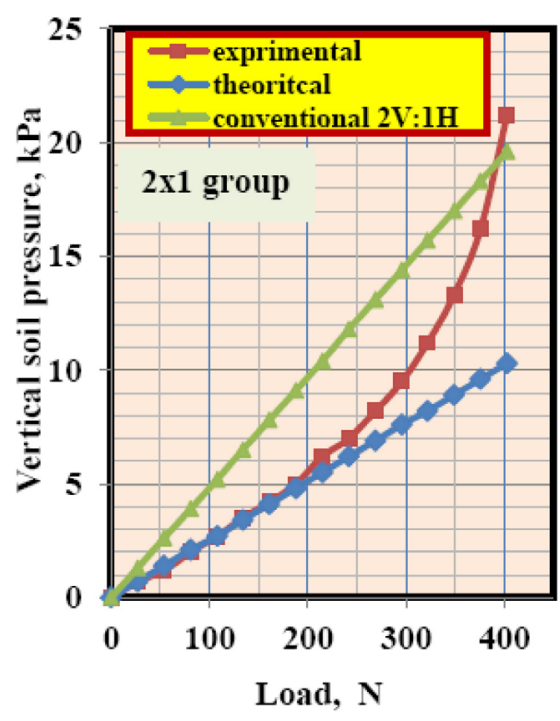

b. $2 \times 1$ group.

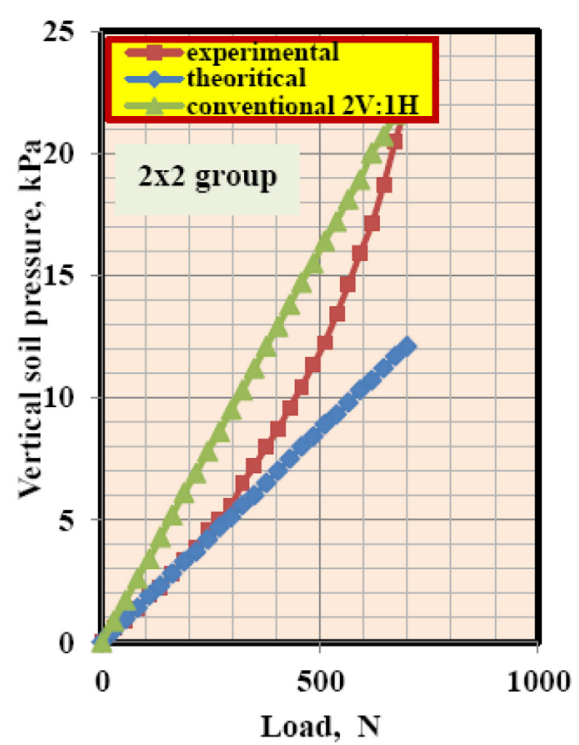

d. $2 \times 2$ group.

Fig. 6 Stress transfer below the pile tip during the load application to pile group in unsaturated soil (S $=60 \%, \gamma_{\mathrm{d}}=17 \mathrm{kN} / \mathrm{m}^{3}$ ) compared with that of theoretical and conventional $2 \mathrm{~V}: 1 \mathrm{H}$ approaches. 


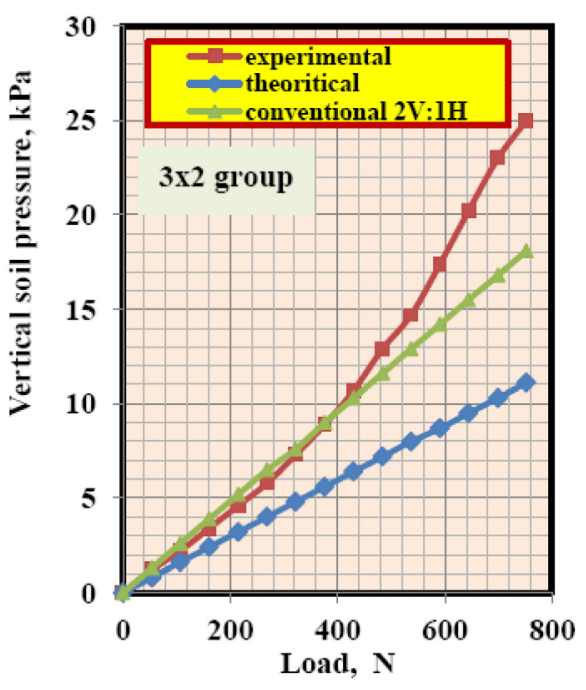

e. $3 \times 2$ group.

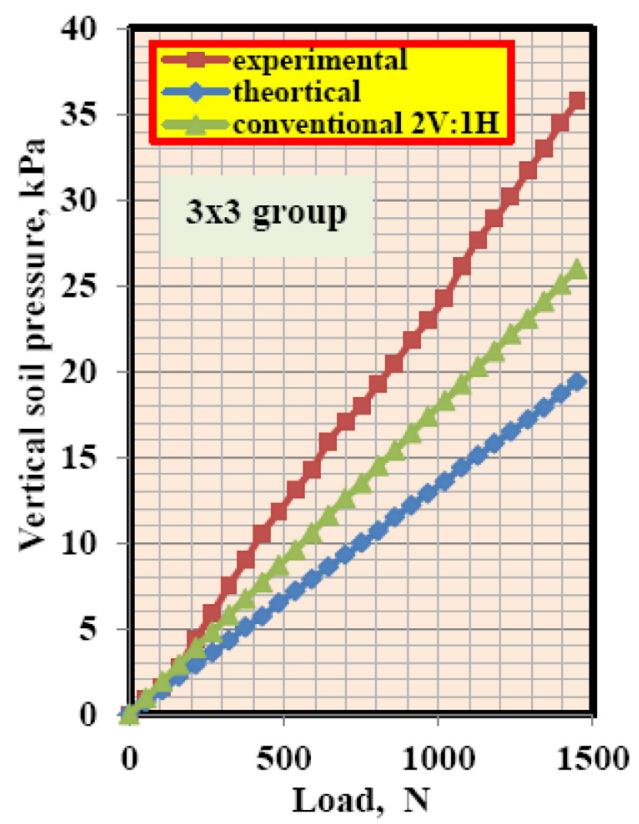

f. $3 \times 3$ group.

Fig. 6: Continued.

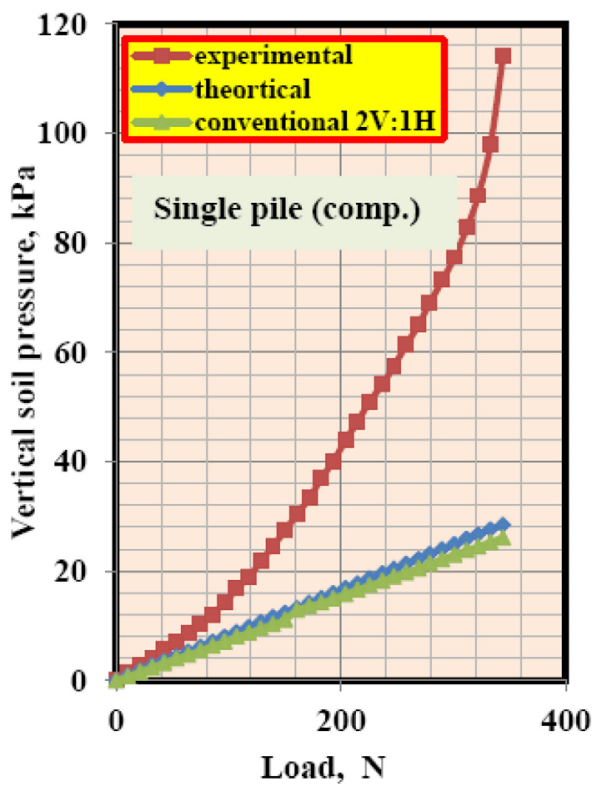

a. Single pile.

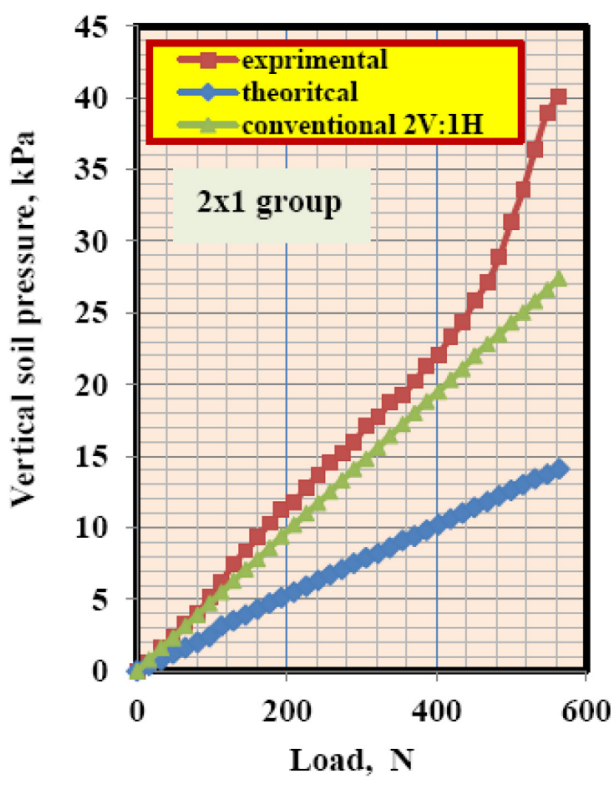

b. $2 \times 1$ group.

Fig. 7 Stress transfer below the pile tip during the load application to pile group in unsaturated soil ( $\mathrm{S}$ $=60 \%, \gamma_{\mathrm{d}}=15 \mathrm{kN} / \mathrm{m}^{3}$ ) compared with that of theoretical and conventional $2 \mathrm{~V}: 1 \mathrm{H}$ approaches. 


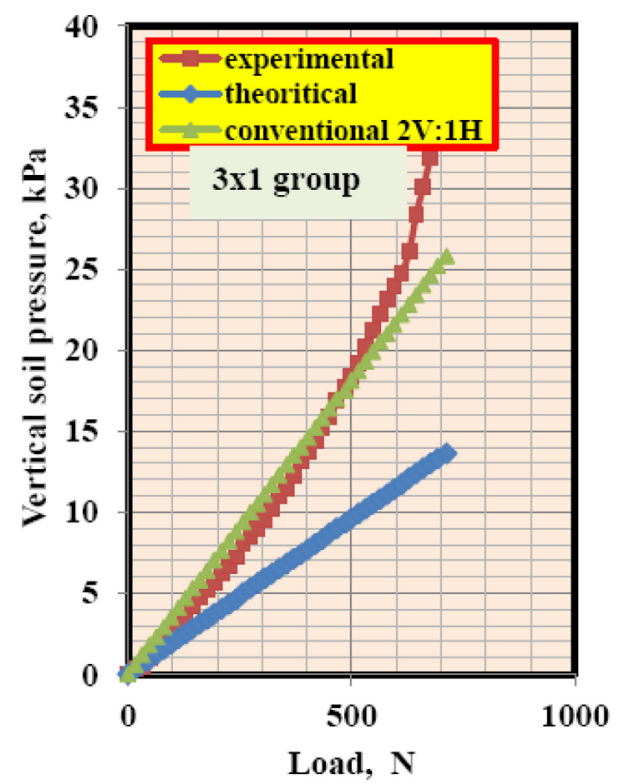

C. $3 \times 1$ group.

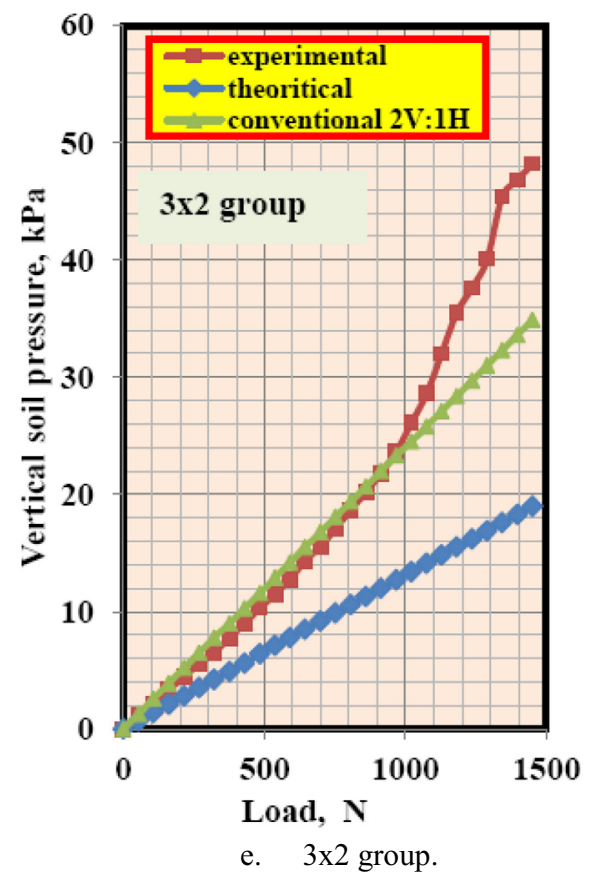

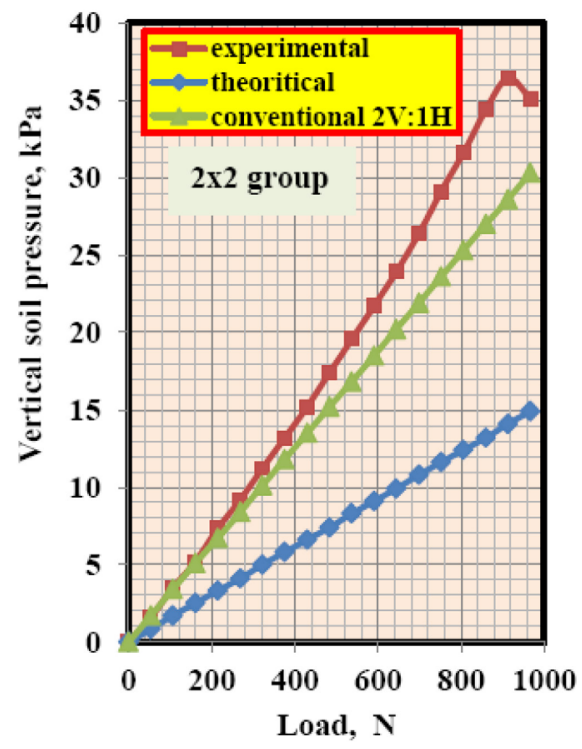

d. $2 \times 2$ group.

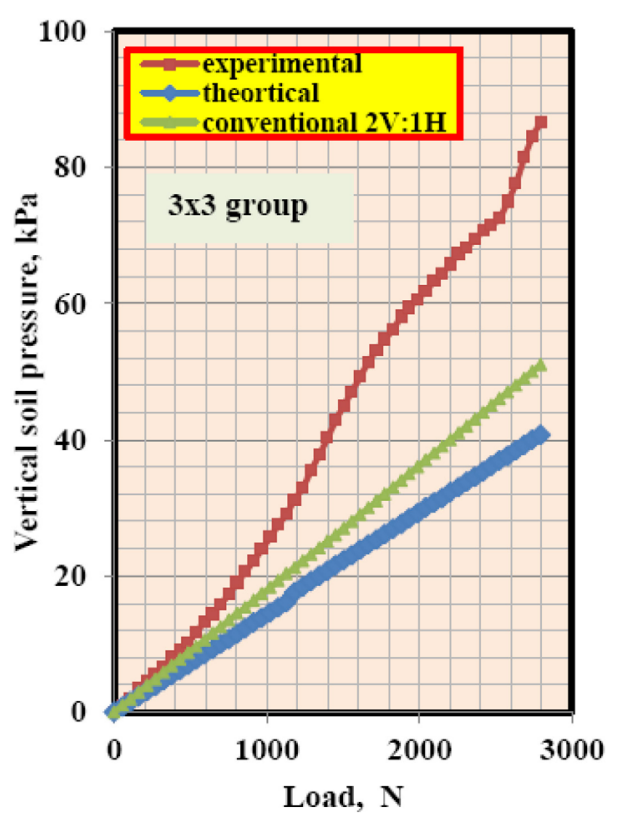

f. $3 \times 3$ group.

Fig. 7 Continued.

The stress transferred is important in the analysis of the pile foundations, since it provides the amount of stress transferred to the underlying soil below and around the pile groups, and consequently, the capacity of the soil to carry these stresses safely. 
However, there is a complexity associated with studying these stresses due to the difficulty accompanying the method for the stresses to be transferred to underlying soil, since this phenomenon is controlled by many factors reviewed in the introduction.

\section{Conclusions}

From the presented figures reviewed, it can be said that the analysis of stress transferred from theoretical approach depends on sharing stresses transferred between the pile and tip and these percent's on most occasions depend on engineering judgment, while the other is the conventional $2 \mathrm{~V}: 1 \mathrm{H}$ method. These two methods give a linear stress transferred results, however, the theoretical method take into account only one parameter of soil property (Poisson's ratio). In contrast, the direct measuring of stress transferred with a soil pressure transducer positioned at $0.25 \mathrm{~L}$ below pile tip through experimental tests, gives a non- linear response for all piles tested with different soil properties, as shown in the figures.

In brief, it can be concluded that the method of measuring the soil stresses with soil pressure transducer adopted in this study, compared with the results obtained from the theoretical and conventional approaches, gives in general, good results of stress transfer, However the theoretical analysis takes only one soil parameter, Poisson's ratio, into account.

\section{References}

1. Fredlund, D.G. and Rahardjo, H., (1993), "Soil Mechanics for Unsaturated Soils". John Wiley, New York.

2. Bowles, J. E., (1996), "Foundation Analysis and Design". McGraw-Hill International Book Company.

3. Rao, N. S. V., (2011), "Foundation Design, Theory and Practice". John Wiley \& Sons (Asia) Pte Ltd, 2 Clementi Loop, 02-01, Singapore.

4. Vanapalli, S. K, and Oh, W.T., (2011), "Interpretation of the Bearing Capacity of an Unsaturated Soils Extending the Effective and Total Stress Approaches", in Proc. 5th Int. Conf. on UNSAT, 2010, pp: 1223-1229.

5. Vanapalli, S. K. and Taylan, Z. N., (2011), "Estimation of the shaft capacity of model piles in a compacted fine-grained unsaturated soil". Proc. 14th Pan-Am Conf. on Soil Mechanics and Geotechnical Engineering \& 64th Canadian Geotechnical Conf.

6. Mohsen, I. M., (2012), "Behavior of Single Pile in Unsaturated Clay Soils". M.Sc. Thesis, Building and Construction Engineering Department, University of Technology, Iraq.

7. Fattah. M. Y., Salim, N. M., Mohsin, I. M., (2014), "Behavior of Single Pile in Unsaturated Clayey Soils". Engineering Technology Journal, Vol.32, Part (A), No.3. pp: 763-787.

8. Fattah, M. Y., Yahya, A. Y., Al-Hadidi, M. Th., Ahmed, B. A., (2013), "Effect of Salt Content on Total and Matric Suction of Unsaturated Soils", European Scientific Journal, Vol. 9, No. 9, pp. 228-245.

9. Khallawi, A.M. (2015), "Load Transfer of Pile Group in Saturated and Unsaturated Clayey Soil”. Ph.D. Thesis, Al-Nahrain University, Baghdad, Iraq.

10. U S Army Corps of Engineers, (1991), "Design of Pile Foundation”. Engineering Manual. 